\title{
Knowledge on seizures and their immediate management among preschool teachers in Colombo district
}

\author{
*Lashan Sanoj Peiris ${ }^{1}$, Dimuthu Saraji Wijesekara ${ }^{2}$, Manori Gamage ${ }^{2}$, Harshitha Siriwardana ${ }^{2}$, Isuri \\ Niwanthika $^{2}$, Hansani Nathaliya Kumarasiri ${ }^{2}$, Chathupani Anuradha Wettasinghe ${ }^{2}$
}

Sri Lanka Journal of Child Health, 2021; 50(4): 681-686

DOI: http://doi.org/10.4038/sljch.v50i4.9887

\begin{abstract}
Introduction: Seizures are common in childhood and need immediate attention. Preschool teachers play a key role in caring for children with seizure disorders. Yet, literature on preschool teachers' knowledge on seizures and first-aid is scarce.
\end{abstract}

Objectives: To assess the knowledge regarding seizures and immediate management and attitudes towards the children with convulsions among preschool teachers in the Colombo District.

Method: A community-based descriptive crosssectional study was carried from April to August 2017 using a pre-tested interviewer-administered questionnaire among 110 preschool teachers from private institutions, selected on a random basis representing all Medical Officers of Health $(\mathrm{MOH})$ areas in Colombo District, Sri Lanka.

Results: One hundred and ten preschool teachers, $96.4 \%$ of whom were female, participated in the study and $76 \%$ had a diploma level qualification in preschool teaching. Majority $(67.3 \%)$ had less than 10 year experience in preschool teaching. Of the respondents, $121(81.8 \%)$ had a good knowledge regarding seizures but only $72(49.1 \%)$ had knowledge regarding first-aid care; $66.4 \%$ of respondents had a good awareness about seizures while $60.9 \%$ of respondents had a poor attitudes towards the children with seizures. Significant correlations were found between the educational level and knowledge as well as previous training on

${ }^{1}$ University of Sri Jayewardenepura, Sri Lanka and National Hospital of Sri Lanka, ${ }^{2}$ University of Sri Jayewardenepura, Sri Lanka

*Correspondence: lashansanojpeiris@gmail.com

iD https://orcid.org/0000-0001-8431-3861

(Received on 07 November 2020: Accepted after revision on 18 December 2020)

The authors declare that there are no conflicts of interest.

Personal funding was used for the project.

Open Access Article published under the Creative

Commons Attribution CC-BY CC (i) License seizure management and the knowledge about seizures.

Conclusions: Of the preschool teachers, $82 \%$ had a good knowledge regarding seizures, $66 \%$ had a good awareness about seizures but only $49 \%$ had knowledge regarding first-aid care and $61 \%$ had a poor attitude towards the children with seizures. Higher level of education and prior training on seizure management significantly correlated with knowledge on seizures.

(Key words: Seizures, Preschool teachers, Knowledge, Immediate management, Convulsions)

\section{Introduction}

Seizure disorders include epilepsy, febrile seizures and seizures secondary to metabolic, infectious, or other causes ${ }^{1}$. Epilepsy has a cumulative life-time incidence of $3 \%^{2}$ and a prevalence of $4.5-5.0$ per $1000^{3}$. Around $4-10 \%$ of children experience at least one seizure in the first 16 years of life $^{4}$. Febrile convulsions, which represent the most common childhood seizure disorder, exists only in associations with an elevated temperature. Epilepsy is commonly treated with regular medications after a second seizure has occurred ${ }^{5,6}$. As a first aid measure, turning a person with a generalised convulsion on to their side helps to prevent fluids from entering the lungs ${ }^{7}$. Inserting fingers, a bite block or tongue depressor into the mouth can make the person vomit or bite the rescuer ${ }^{7,9}$. Further selfinjury should be prevented ${ }^{9}$. Seizure lasting longer than 5 minutes or more than two seizures in an hour without regaining consciousness in-between is called status epilepticus ${ }^{6,11}$. This may need insertion of a nasopharyngeal airway to keep the airway open and protected ${ }^{6,7}$. At home, the initial medication recommended for a prolonged seizure is midazolam placed in the mouth or diazepam used rectally ${ }^{12}$. In hospital, intravenous lorazepam is preferred ${ }^{12}$. A significant number of children in urban areas spend most of their daytime in preschools due to the modern life style. Preschool teachers play a key role in caring for children with seizures because they are the people who first encounter a convulsion. Knowledge and attitudes of preschool teachers regarding seizure disorders and on first aid care in such situations has an important impact on 
continuation of schooling in children with seizure disorders.

\section{Objectives}

General Objective

To assess the knowledge regarding seizures and immediate management and attitudes towards the children with convulsions among preschool teachers in the Colombo District.

\section{Specific Objectives:}

- To assess the knowledge on identification of a convulsion in preschool teachers.

- To assess the knowledge on immediate first-aid management of a convulsion in preschool teachers.

- To evaluate the attitude towards the children with convulsions among preschool teachers.

- To identify the association between demographic data and the knowledge on convulsions and its immediate management.

\section{Method}

We carried out a descriptive cross-sectional study to assess the knowledge regarding convulsions and their immediate management among preschool teachers who were working in the Colombo District, Sri Lanka. We interviewed 110 preschool teachers from private institutions, selected on a random basis representing all Medical Officers of Health $(\mathrm{MOH})$ areas in Colombo District, Sri Lanka.

The used interviewer administered questionnaire contained socio-demographic information, questions to assess the knowledge on convulsions, first-aid care for a convulsion and attitudes towards the children with seizures. The preliminary questionnaire was pre-tested in a pilot survey of 10 randomly selected preschool teachers in Colombo district, Sri Lanka. The survey was conducted from April to August 2017.

Ethical issues: Ethical clearance was obtained from the Ethics Review Committee of the Faculty of Medical Sciences, University of Sri Jayewardenepura (No. 34/16) on 20.07.2016. Written informed consent was obtained from all the participants. All assessments were performed anonymously. Confidentiality was maintained at all levels.

Statistical analysis: This was done using IBM SPSS Statistics version 21.0 (IBM Corporation, Armonk, New York, USA) and Microsoft Office Excel 2010 (Microsoft Corporation, Redmond, Washington, USA).

\section{Results}

During the study period, 110 questionnaires were completed among preschool teachers who were selected from the private-owned preschools. The demographic characteristics are shown in Table 1.

Table 1: Demographic characteristics $(n=110)$

\begin{tabular}{|l|c|}
\hline \multicolumn{1}{|c|}{ Characteristic } & Number (\%) \\
\hline Gender & $04(03.6)$ \\
Male & $106(96.4)$ \\
Female & \\
\hline Nationality & $88(80.0)$ \\
Sinhala & $05(04.5)$ \\
Hindu & $14(12.7)$ \\
Muslim & $03(02.8)$ \\
Burgher & \\
\hline Home town & $100(90.9)$ \\
Colombo Pre-school & $10(09.1)$ \\
Out of Colombo & $83(75.5)$ \\
\hline Educational status & $05(04.5)$ \\
O/L & \\
A/L & \\
Diploma in & \\
teaching & \\
Graduated & $70(63.6)$ \\
\hline Marital status & $40(36.4)$ \\
Married & \\
Unmarried & $63(57.3)$ \\
\hline Having children or not & $47(42.7\}$ \\
Yes & $76(69.1)$ \\
No & $34(30.9)$ \\
\hline Status of the teachers & $22(13.6)$ \\
Permanent Teacher & $04(03.6)$ \\
Assistant teacher & \\
\hline Duration of & \\
experience & \\
$<1$ year & \\
1-5yrs & \\
5-10yrs & \\
10-15yrs & \\
15-20yrs & \\
>20yrs & \\
\hline
\end{tabular}

Participants' knowledge on identification of a seizure and immediate first-aid care:

Significant correlations were noted between the educational level and knowledge $(p=0.039, p<0.05)$ and previous training on fit management and knowledge $(\mathrm{p}<0.05)$. Majority $(92 \%)$ of them never had any prior training regarding seizure management. Among them, $81.8 \%$ of the study population had never encountered a child with seizures, $82 \%$ considered seizure to be a physical illness and $10 \%$ considered it to be a result of mental illness or due to evil spirits (Table 2). Perceived adequacy of knowledge and skills to manage a fit competently was seen among $49 \%$ of the teachers (Table 2). Two thirds of them $(66.4 \%)$ were aware of seizures previously and among them $41 \%$ got information from the television and radio (Table 2). 
Table 2: Characteristics of teachers with regards to fits

\begin{tabular}{|l|c|}
\hline \multicolumn{1}{|c|}{ Characteristic } & Number (\%) \\
\hline Encountered a child with fits previously & 18.2 \\
Yes & 81.8 \\
No & 81.8 \\
\hline What is a fit? & 10.0 \\
Physical illness & 08.2 \\
Mental illness & \\
Physical + Mental illness & 66.4 \\
\hline Have you heard about fits before? & 33.6 \\
Yes & \\
No & 18.1 \\
\hline Source of awareness about fits & 23.6 \\
Books & 40.9 \\
Newspapers & 07.2 \\
TV/Radio & 07.2 \\
Seminar & 03.4 \\
Experience & 49.1 \\
Internet & 50.9 \\
\hline Perceived adequacy of knowledge and skills to manage a fit & \\
Yes & \\
No & \\
\hline
\end{tabular}

Out of the respondents, $81.8 \%$ had a good knowledge regarding convulsions but only $49.1 \%$ had knowledge regarding immediate first-aid measures (Table 3).

Table 3: Knowledge of first aid during a fit

\begin{tabular}{|l|c|}
\hline \multicolumn{1}{|c|}{ First aid measure } & Number (\%) \\
\hline Position of the fitting child & 72.7 \\
Lateral & 13.6 \\
Supine & 08.2 \\
Prone & 05.5 \\
Don't know & \\
\hline Handling sections & 61.8 \\
Wipe out & 09.1 \\
Don't wipe & 29.1 \\
Don't know & \\
\hline Handling cloths & 83.6 \\
Remove tight cloths & 03.6 \\
Keeps cloths as they were & 12.7 \\
Don't know & \\
\hline Carrying the child during a fit & 68.2 \\
Lateral & 13.6 \\
Supine & 02.7 \\
Prone & 10.0 \\
Carrying & 05.5 \\
Don't know & \\
\hline What to do after resolving fit & 76.4 \\
Take for medical care & 15.5 \\
Send the child home & 02.7 \\
Continue routine as normal & 0.9 \\
Inform patients & 04.5 \\
Don't know &
\end{tabular}

Whilst $72.7 \%$ knew that the child should be kept in the lateral position while fitting, $5.5 \%$ did not know what position the child should be kept in during a fit; $40(36.4 \%)$ teachers said that they should put a spoon or finger while the child is fitting. Wiping out secretions was approved by $61.8 \%$ of the teachers and $83.6 \%$ said that they have to remove tight clothes while child is having a fit. Of the teachers, $76.4 \%$ said that the child should be taken to medical care after every fit. Only $2.7 \%$ said that they can 
continue daily normal routine of the child; $93.1 \%$ of teachers believed that a child after a fit requires special attention in tasks which can lead into injury.

Half of the study group (50.9\%) did not agree that the child should be doused in water or should be given anything orally $(51.8 \%)$. One third $(34.5 \%)$ said that metal object is given to be handled during a fit (Table 4). When inquired about what should be done after a fit, $58.0 \%$ of them said that it was better not to wait at home and to seek medical advice immediately whereas $5.5 \%$ said that they can wait for 15 minutes till the fit has resolved spontaneously for medical advices to be taken; $68.2 \%$ said that the child should be carried in the lateral position (Table 3). Almost all (99.1\%) did not know any medication as a primary treatment modality for a fit.

Table 4: Wrong practices during a fit

\begin{tabular}{|l|c|}
\hline \multicolumn{1}{|c|}{ Wrong practice } & Number (\%) \\
\hline Putting a spoon inside the mouth & 36.4 \\
Put a spoon or a finger & 51.8 \\
Don't put anything in mouth & 11.8 \\
Don't know & \\
\hline Douse the child with water or not & 15.5 \\
Yes & 50.9 \\
No & 33.6 \\
Don't know & \\
\hline Giving oral medications & 17.3 \\
Yes & 51.8 \\
No & 30.9 \\
Don't know & \\
\hline
\end{tabular}

Awareness about convulsions was better in $66.4 \%$, while attitudes towards the children with convulsions were poor in $0.9 \%$. When considering the knowledge of evaluation of symptoms of a fit, more than $72.7 \%$ had adequate knowledge in each category of symptoms; frothing $(86.4 \%)$, tonic- clonic movements $(82.7 \%)$, eyes rolling up $(79.1 \%)$, lateral tongue bite $(74.5 \%)$, jerky movements $(73.6 \%)$ and drooling of saliva (72.7\%) were identified correctly as features of a fit (Figure 1). Out of them $41.8 \%$ did not know that staring at a point was a clinical symptom of fit.

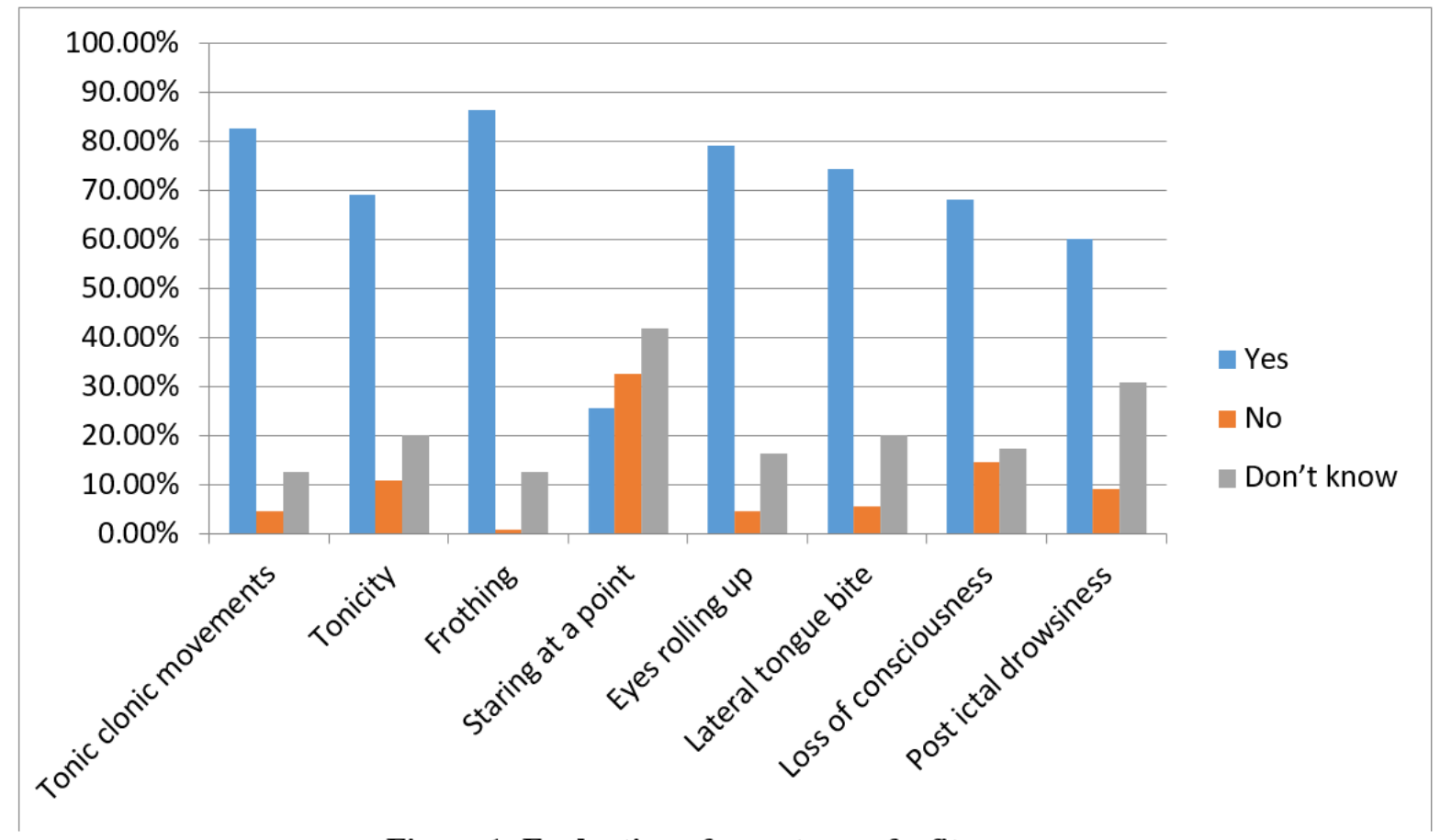

Figure 1: Evaluation of symptoms of a fit

\section{Discussion}

As per our primary objective to assess the knowledge regarding convulsions and its immediate management, we noted that $66.4 \%$ of teachers were aware of fits prior to the study. This is in contrast to an Indian study conducted in 2013 among 85 teachers, where more than $90 \%$ of them were aware of fits ${ }^{14}$. Majority of our study population had 
obtained information regarding fits from television (TV) and radio (41\%) which is different from international studies. A study done in Saudi Arabia regarding knowledge and practices of school teachers towards students with epilepsy showed that the main sources of information were friends and relatives $(36.8 \%)$ while $\mathrm{TV}$ and radio was in the third place ${ }^{16}$. A Brazilian study under the same purview disclosed that most informative sources were newspapers and magazine articles $(65 \%)^{12}$.

It is satisfying to find that the knowledge about symptoms of a fit is adequate among the study group. More than $72.7 \%$ of them identified the cardinal symptoms of a fit. This is in par with the above Brazilian study, which found that $75 \%$ of teachers had adequate knowledge on symptoms of a seizure. Furthermore, similar findings were noted in a study in Chandigarh city, India ${ }^{14}$ where it was found that the majority of teachers were aware of symptoms of epilepsy (rhythmic jerky movements $72 \%$, loss of consciousness $78 \%$ ). Majority of our respondents were not aware that 'staring at a point' is a feature of a fit. This is significant as absence seizures are common among preschoolers. This in stark contrast with the findings of the aforementioned Indian study where $85 \%$ of teachers identified 'looking blank' as a symptom of a fit followed by 'rapid eye blinking' (12\%).

In the area pertaining to knowledge regarding first aid, they had satisfactory knowledge with regards to the position that the child should be kept $(72.7 \%)$, to avoid putting metals or fingers into mouth, to wipe out secretions from mouth $(61.8 \%)$ and removal of tight clothing (88.6\%). These results were similar to the findings that were found in the Brazilian study on teachers' perception about epilepsy ${ }^{12}$. Even though they knew what should be done during a fit, half the population did not think that they have adequate skills to manage a fitting child. This can be due to the fact that $81.8 \%$ of the population have never encountered a child with fits or having a fit and $92 \%$ of them have not had prior training in first aid for a fit. These percentages are more than what was found in a research done among 315 school teachers in Saudi Arabia in 2015, where it was found that $64.1 \%$ of teachers did not provide first aid to a child having seizures as $65.7 \%$ of teachers were not equipped to give first aid.

There is still a belief among teachers that the child should be doused in water $(49.1 \%)$, metals should be given to be handled $(34.5 \%)$ and oral medication should be given (17.3\%). These were wrong practices and therefore were discouraged and the do's and don'ts were emphasized in this group. Similar kind of erroneous practices were seen among $33 \%$ of preschool teachers in Germany ${ }^{10}$ where they put something hard inside the child's mouth. It is evident that most teachers display average to good basic knowledge regarding seizures in children. However, there is inadequate knowledge on acute management of a seizure at their preschools. Therefore it is recommended that Sri Lankan teachers should be given more knowledge regarding basic first aid management on management of seizures through a 'hands on' skill workshop.

\section{Conclusions}

Of the preschool teachers, $82 \%$ had a good knowledge regarding seizures, $66 \%$ had a good awareness about seizures but only $49 \%$ had knowledge regarding first-aid care and $61 \%$ had a poor attitudes towards the children with seizures. Higher level of education and prior training on seizure management significantly correlated with knowledge on seizures.

\section{References}

1. Kliegman RM, Stanton BF, ST. Geme JW, Behrman RE, Schor NF. Nelson Textbook of Paediatrics $19^{\text {th }}$ edition; chapter $586-$ Seizures in childhood; page 2013-39.

2. Bhesania NH, Rehman A, Savul IS, Zehra N. Knowledge, attitudes and practices of school teachers towards epileptic school children in Karachi, Pakistan. Pakistan Journal of Medical Sciences 2014; 30(1): 220224

https://doi.org/10.12669/pjms.301.4307

PMid: 24639865 PMCid: PMC3955576

3. Forsgren L, Beghi E, Oun A. The epidemiology of epilepsy in Europe - a systematic review. European Journal of Neurology 2005; 12:245-53.

https://doi.org/10.1111/j.14681331.2004.0 0992.x

PMid: 15804240

4. Karimi N, Heidavi M. Knowledge and attitudes towards epilepsy among school teachers in west of Iran; Iranian Journal of Neurology 2015; 14(3): 130-5.

5. Baumann RJ, Kao A. Paediatric febrile seizures. Available from:

https:/emedicine.medscape.com/article/11 76205-overview

6. National Institute of Neurological Disorders and Stroke. Available from: http://www.ninds.nih.gov/index.htm

7. Micheal GE, O'Connor RE. The diagnosis and management of seizures and status 
epilepticus in the pre hospital setting. Emergency Medicine Clinics of North America 2011; 29(1): 29-39.

https://doi.org/10.1016/j.emc.2010.08.003 PMid: 21109100

8. Iloeje SO. The impact of socio-cultural factors on febrile convulsions in Nigeria; West African Journal of Medicine 1989; 8(1): 54-8.

9. Shearer P. Seizures and status epilepticus: Diagnosis and management in the emergency department; Emergency Medicine Practice 2006; 8(8):

10. Dumeier HK, Neininger MP, Bernhard MK, Syrbe S, Merkenschlager A, Zabel J, et al. Knowledge and attitudes of school teachers, preschool teachers and students in teacher training about epilepsy and emergency management of seizures; Archives of Disease in Childhood 2015; 100: 851-5.

https://doi.org/10.1136/archdischild-2015308306

PMid: 26111815

11. Wheless JW, Willmore J, Brumback RA. Advanced therapy in epilepsy; Shelton, Conn.: People's Medical Pub. House. Page 144.

12. Fernandes PT, Noronha ALA, Araujo U, Cabral P, Pataro R, De boer HM, et al. Teachers perception about epilepsy; Arq. Neuro-Psiquiatr. 2007; 65(suppl.1): 28-34. https://doi.org/10.1590/S0004282X20070 01000005

PMid: 17581665
13. The epilepsies: The diagnosis and management of the epilepsies in adults and children in primary and secondary care; National clinical guideline centre. London: Royal College of Physicians (UK); 2012 January.

14. Goel S, Singh N, Lal V, Singh A Evaluating the impact of comprehensive epilepsy education programme for school teachers in Chandigarh city, India. Seizure 2014; 23(1): 41-6. https://doi.org/10.1016/j.seizure.2013.09.0 10

PMid: 24135443

15. Albilhamail AS, Al-Sulami FE, Alnouri MA, Mahrous MN, Joharji DG, Albogami $\mathrm{MM}$, et al. Primary school teachers knowledge and attitudes toward children with epilepsy. Seizure 2014; 23: 280-3. https://doi.org/10.1016/j.seizure.2013.12.0 10

PMid: 24445017

16. Algahtani J.M. Knowledge and practice of schoolteachers towards students with epilepsy in Khamis Mushate, Southern Saudi Arabia. Journal of Family and Community Medicine 2015; 22(3): 163-8. https://doi.org/10.4103/2230-8229.163034 PMid: 26392797 PMCid: PMC4558738 